\title{
Role of Videonystagmography (VNG) in Epley's Maneuver
}

\author{
Saloni Shah ${ }^{*}$, Rajesh Vishwakarma ${ }^{2}$ \\ ${ }^{1}$ Civil Hospital, B.J. Medical College, Ahmedabad, India \\ ${ }^{2}$ ENT Department, Civil Hospital, B.J. Medical College, Ahmedabad, India \\ Email: drsaloni155@gmail.com
}

Received 6 August 2014; revised 5 September 2014; accepted 4 October 2014

Copyright (C) 2014 by authors and Scientific Research Publishing Inc.

This work is licensed under the Creative Commons Attribution International License (CC BY). http://creativecommons.org/licenses/by/4.0/

(c) () O) Open Access

\begin{abstract}
Aims and Objectives: To study benefit of videonystagmography in confirmation of canalolith repositioning in patients with Benign Paroxysmal Positional Vertigo after Epley's manouver. Study Design: Prospective study of 35 cases of BPPV. Materials and Method: 35 patients of BPPV presenting at vertigo clinic of ENT department at Civil Hospital Ahmedabad were treated with canalolith repositioning procedure and improvement in nystagmus was studied and confirmed by VNG. Observation: 31 patients out of 35 patients were improved with $1^{\text {st }}$ CRP, 2 out of 3 patients improved with $2^{\text {nd }}$ CRP and 1 patient improved with $3^{\text {rd }}$ CRP. This improvement is confirmed using VNG. Conclusion: Videonystagmography is a very useful tool for ensuring the otolith repositioning by the canalith repositioning manouver. It is a confirmatory adjunct to visual analysis.
\end{abstract}

\section{Keywords}

BPPV, Epley's Manouver, Videonystagmography

\section{Introduction}

BPPV (Benign Paroxysmal Positional Vertigo) is the most common cause of vertigo. It is typically described as a brief, intense sensation of spinning that occurs when there are changes in the position of the head with respect to gravity. An individual may experience BPPV when rolling over to the left or right, upon getting out of bed in the morning. It is due to the presence of normal but misplaced calcium crystals called otoconia, which are normally found in the utricle and saccule (the otolith organs) and are used to sense movement. If they fall from the utricle and become loose in the semicircular canals, they can distort the sense of movement and cause a mismatch between actual head movement and the information sent to the brain by the inner ear, causing a spinning

${ }^{*}$ Corresponding author. 
sensation. It affects vestibulo-ocular reflex and produce nystagmus [1]-[4].

Head movement $->$ SCC moves $->$ signal via $8^{\text {th }}$ nerve to vestibular nuclei $->$ send impulse to $6^{\text {th }}$ nerve to medial rectus $->$ cause eye movements [4].

Videonystagmography (VNG) is useful to test balance system and record nystagmus by a camera. There are neural connections that stretch balance mechanisms in inner ear to muscles of eye. Any disorder of balance mechanism produces small eye jerks that can only be detected by computer and frenzel's goggles [5] [6]. It can be monitored by putting body in different positions by Dix Hallpike's test and Roll Over test. VNG is a test used to determine whether or not dizziness may be due to inner ear disease. It also assesses the function of the vestibular end organs, central vestibulo-occular pathway and oculomotor processes.

Most commonly involved SCC is horizontal due to its anatomical location. During Dix Hallpike's test the rotatory nystagmus, in the form of twitching movements directed towards the affected ear, is seen after 5 to 10 seconds and it disappears in 45 seconds [7] [8].

Epley's maneuver (canalith repositioning procedure-CRP) [1]-[3] [9]-[11] is to reposit otoconia from abnormal position of SCC to normal in utricle. This maneuver was developed by Dr. John Epley and first described in 1980.

Several articles have been published on efficacy and utility of CRP for treatment of BPPV [12]. It is widely accepted that CRP can result in substantial benefit with very low recurrence rate on short- and long-term outcomes basis. The common factors responsible for recurrence are hormones, calcium metabolism and trauma.

\section{Aims and Objectives}

To study the benefit of use of videonystagmography for confirmation of repositioning of otolith by Epley's manouvere by noting the improvement in nystagmus and vertigo in patients with BPPV [13]-[16].

\section{Materials and Method}

- In this prospective study 35 patients suffering from BPPV presented in vertigo clinic at our institute between July 2012 to April 2014 were enrolled.

- Inclusion criteria: positive history of positional vertigo, confirmed with Dix hallpike's test and nystagmus is recorded with VNG.

- Exclusion criteria: patients with spinal disease, hypertension/hypotension, heart disease, neurological diseases, central lesions confirmed on history, physical examination in the form of neurological tests-reflexes, cranial nerve examinations, X-ray, CT or MRI.

\section{Procedure}

- Patients were first allowed to sit for 5 mins to get relaxed from anxiety.

- Patients were left in position during Dix Hallpike's test for 45 seconds and provoked nystagmus is recorded on VNG.

Then CRP was done and VNG recording was continued to see improvement in nystagmus.

Patient was advised to take bed rest, not to bend over and no head shaking movements.

- Follow up done on $7^{\text {th }}, 14^{\text {th }}, 21^{\text {st }}$ day to see improvement of nystagmus and if provocative maneuver was positive on follow-up evaluation, the CRP was repeated and follow up VNG done.

- Patients which improved were followed up every three monthly.

- Some patients came for follow up for 6 months to 1 year and then were lost for follow up.

\section{Results}

- At the time of presentation, duration of symptoms varied from 3 months to 1 year.

- VNG showed improvement in nystagmus immediately in 31 patients after $1^{\text {st }} \mathrm{CRP}$.

- 3 patients showed improvement on VNG with $2^{\text {nd }}$ CRP and 1 with $3^{\text {rd }}$ CRP (see Figure 1 ).

Table 1 and Graph 1 show that $88.5 \%$ patients improved with $1^{\text {st }}$ CRP which was recorded on VNG, 8.5\% patients improved with $2^{\text {nd }} \mathrm{CRP}$ and $2.8 \%$ patients improved with $3^{\text {rd }} \mathrm{CRP}$.

Table 2 and Graph 2 show that out of 35 patients 31 patients shows improvement both clinically and in videonystagmography after $1^{\text {st }} \mathrm{CRP}$. 


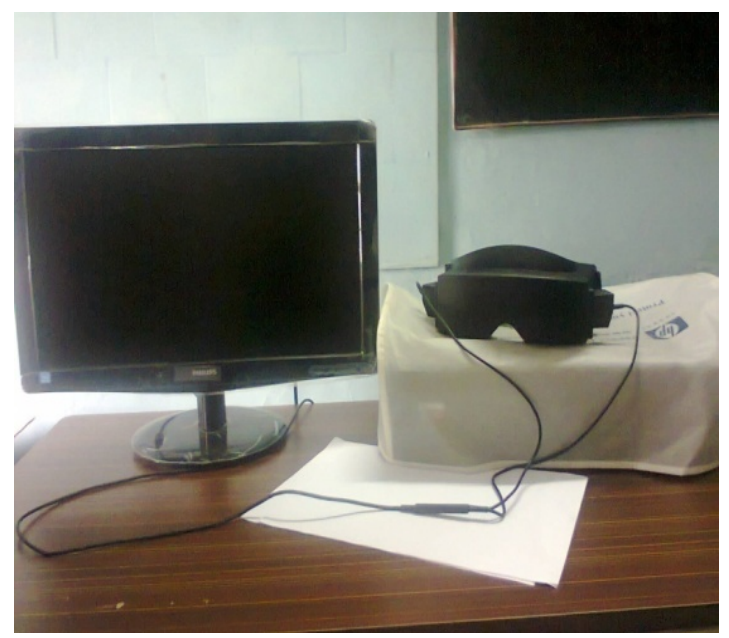

Figure 1. VNG machine.

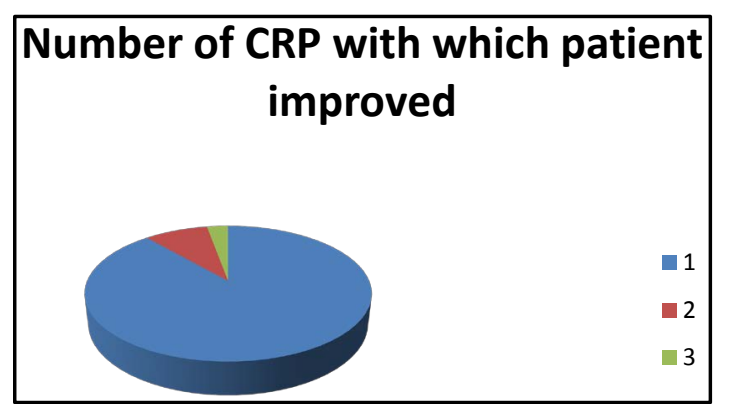

Graph 1. Graphical presentation of above table.

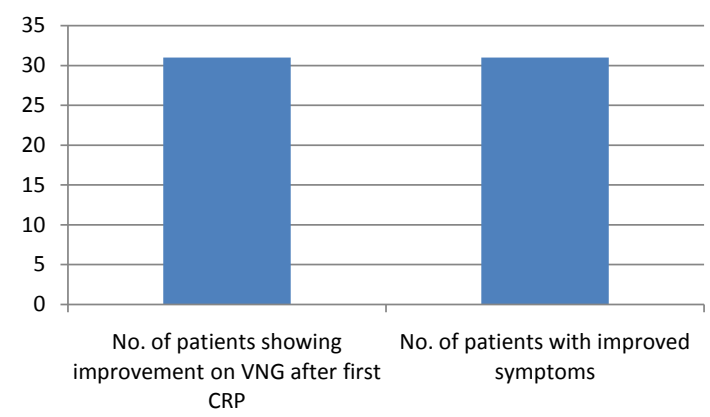

Graph 2. Graphical presentation of above table.

Table 1. Improvement with number of canalith repositioning procedure-CRPs observed in videonystagmography.

\begin{tabular}{cc} 
Number of patients $(\mathrm{n}=35)$ & Number of CRP with which patient improved \\
\hline $31(88.5 \%)$ & 1 \\
$3(8.5 \%)$ & 2 \\
$1(2.8 \%)$ & 3 \\
\hline
\end{tabular}

Table 2. Patients showing improvement both clinically and in videonystagmography after first canalith repositioning procedure-CRP.

No. of patients showing improvement on VNG after first CRP

31
No. of patients with improved symptoms

31 
Table 3 and Graph 3 show that out of remaining 3 patients 2 patients shows improvement both clinically and in videonystagmography after $2^{\text {nd }} \mathrm{CRP}$.

Immediate adverse effects after $1^{\text {st }} \mathrm{CRP}$ were light headedness and nausea for few hours $(1-2)$ seen in 15 patients.

2 patients out of 3 improved with $2^{\text {nd }}$ CRP were older than 65 yrs. 1 patient improved with $3^{\text {rd }}$ CRP had history of head trauma [9]-[11].

\section{Interpretation of VNG}

Electrical signals from the data obtained from the infrared camera (VNG) are fed into the computer to create a digital readout. On the horizontal channel, movement up indicates an eye movement to the right and movement down indicates an eye movement to the left. On the vertical channel, movement up indicates an eye movement up and movement down indicates an eye movement down (shown in Figures 2-4) [5] [6].

Table 3. Patients showing improvement both clinically and in videonystagmography after second canalith repositioning procedure-CRP.

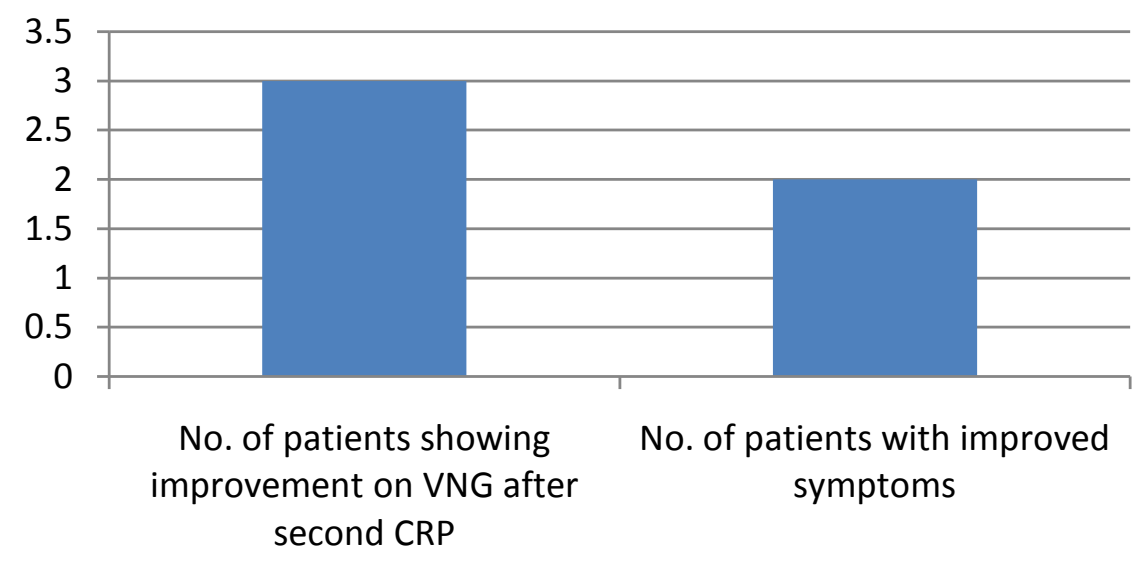

Graph 3. Graphical presentation of above table.

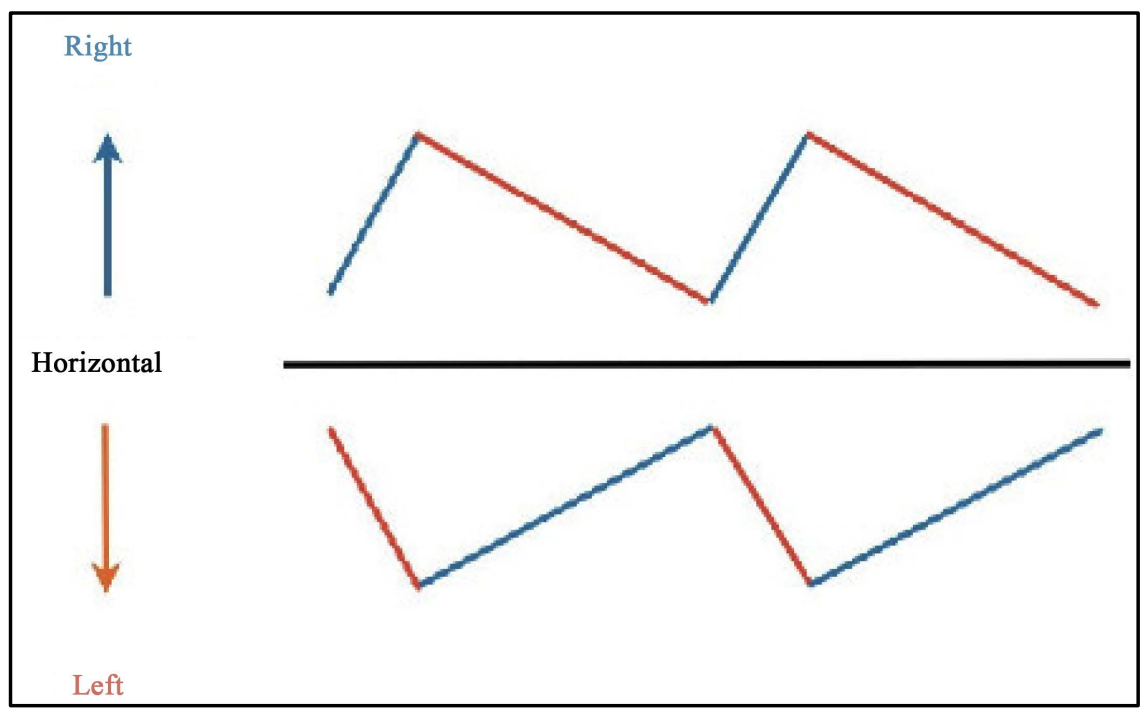

Figure 2. Interpretation of horizontal channel nystagmus. 


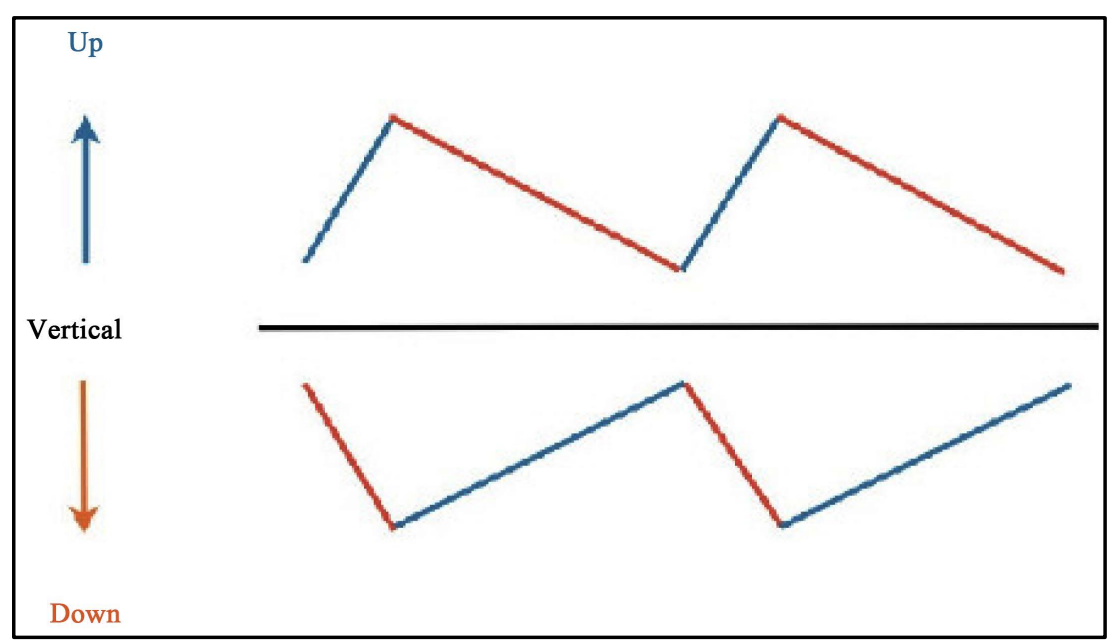

Figure 3. Interpretation of vertical channel nystagmus.

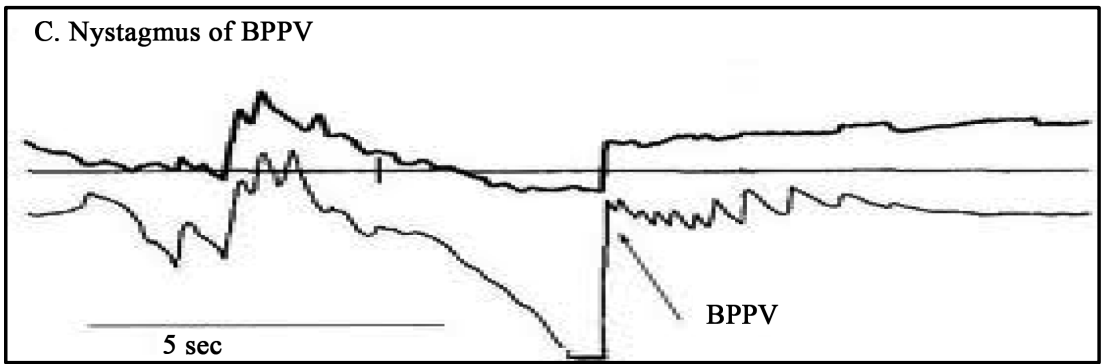

Figure 4. Nystagmus of BPPV [8].

Graph 4 shows nystagmus (arrow) after 7 seconds in a patient with BPPV which lasted for around 45 seconds.

Then CRP was done, followed by repeat VNG.

Graph 5 is post CRP VNG showing improvement in nystagmus (arrow).

\section{Discussion}

The canalith theory suggests that the gravity dependent movement of heavier otoconial debris from utricle to lateral semicircular canal is responsible for vertigo. The crystals themselves can adhere to a semicircular canal cupula making it heavier than the surrounding endolymph. The semicircular canal is weighted down by the dense particles thereby inducing an immediate and maintained excitation of semicircular canal afferent nerves. This condition is termed as cupulolithiasis. Recent concept has suggested that major pathologic change in BPPV is degeneration of vestibular neurons. This results in loss of inhibition of otolith organs on canal activation. The recurrence rate of BPPV is 27\%, and relapse largely occurs in the first 6 months [1]-[4].

VNG can record spontaneous, positional, gaze and optokinetic nystagmus as well as saccadic movements [5] [6]. Dix hallpike's test can check posterior canal of lower ear, anterior canal of opposite ear and lateral canals of both the ears at 45 degree. While the patient is in supine position and head moves to one side, a direction changing nystagmus is observed and it is indicative of,

- Horizontal canal BPPV-nystagmus intense with long duration.

- Central BPPV-verticle component of nystagmus with less duration.

Minimum duration of observation for nystagmus is 20 seconds. It is observed that lateral semicircular canal stimulation gives horizontal nystagmus and anterior or posterior semicircular canal stimulation gives torsional nystagmus.

Positional test performed with patient in sitting and supine position with Dix hallpike's test. The following results are seen. 


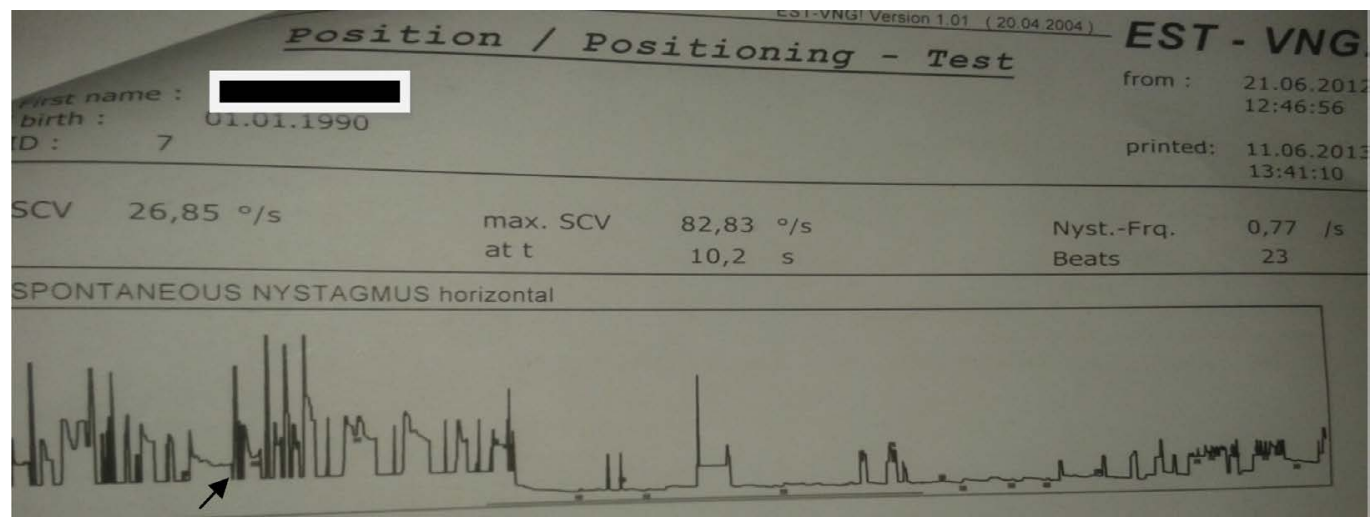

Graph 4. Nystagmus (arrow) after 7 seconds in a patient with BPPV (benign paroxysmal positional vertigo).

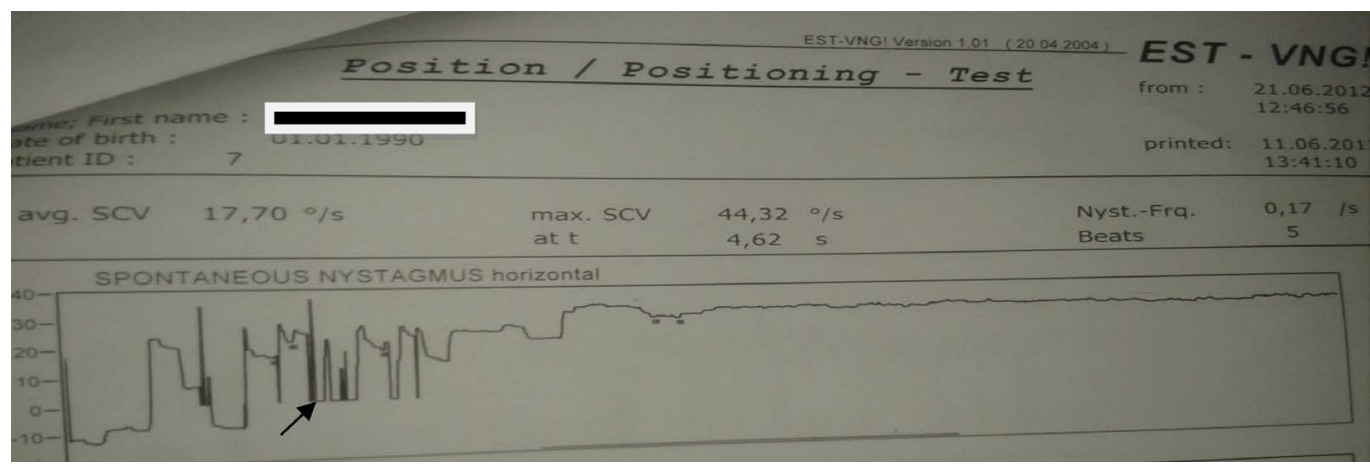

Graph 5. Post canalith repositioning procedure-CRP, videonystagmography.

- Direction changing-Horizontal canal BPPV.

- Direction fixed-uncompesated unilateral vestibular pathology.

Central positional nystagmus does not have a central component and it is not inhibited by fixation [8] [11] [12].

In our patients out of 35 patients 31 improved and 4 patients didn't improve. This may be due to increased age of patients, multiple canaloliths, non-repositioning of otoliths, inefficient CRP or other co-morbidities.

The ENG test relies on the corneoretinal potential to detect the changes in eye position, where as the VNG uses infrared cameras to detect the same. Thus the ENG is an indirect evaluation of the ocular motility, where as the VNG is a direct one [17]-[20].

\section{References}

[1] Brandt, T., Steddin, S. and Daroff, R.B. (1994) Therapy for Benign Paroxysmal Positioning Vertigo, Revisited. Neurology, 44, 796-800.

http://vestibular.org/understanding-vestibular-disorders/types-vestibular-disorders/benign-paroxysmal-positional-vertig o\#sthash.WngZxHF9.dpuf http://dx.doi.org/10.1212/WNL.44.5.796

[2] Fife, T.D., Iverson, D.J., Lempert, T., Furman, J.M., Baloh, R.W., Tusa, R.J., Hain, T.C., Herdman, S., Morrow, M.J. and Gronseth, G.S. (2008) Practice Parameter: Therapies for Benign Paroxysmal Positional Vertigo (an EvidenceBased Review): Report of the Quality Standards Subcommittee of the American Academy of Neurology. Neurology, 70, 2067-2074.

http://vestibular.org/understanding-vestibular-disorders/types-vestibular-disorders/benign-paroxysmal-positional-vertig o\#sthash.WngZxHF9.dpuf http://dx.doi.org/10.1212/01.wnl.0000313378.77444.ac

[3] Epley, J.M. (1992) The Canalith Repositioning Procedure: For Treatment of Benign Paroxysmal Positional Vertigo. Otolaryngology—Head and Neck Surgery, 107, 399-404. 
[4] Gacek, R.R. (2003) Pathology of Benign Paroxysmal Positional Vertigo Revisited. Annals of Otology, Rhinology Laryngology, 112, 574-582. http://www.mm3admin.co.za/documents/docmanager/6e64f7e1-715e-4fd6-8315-424683839664/00021518.pdf

[5] Vitte, E. and Sémont, A. (1995) Assessment of Vestibular Function by Videonystagmoscopy. Journal of Vestibular Research, 5, 377-383. http://dx.doi.org/10.1016/0957-4271(95)00008-4

[6] Mekki, S. (2014) The Role of Videonystagmography (VNG) in Assessment of Dizzy Patient. Egyptian Journal of Otolaryngology, 30, 69-72. http://dx.doi.org/10.4103/1012-5574.133167

[7] Fife, T.D. (2009) Benign Paroxysmal Positional Vertigo. Seminars in Neurology, 29, 500-508.

http://www.medscape.com/viewarticle/714335_3

http://dx.doi.org/10.1055/s-0029-1241041

[8] Hain, T.C. (2009) The Dix-Hallpike Test, Definitive Diagnostic Test for Benign Paroxysmal Positional Vertigo (BPPV). http://www.dizziness-and-balance.com/disorders/bppv/dix\%20hallpike.htm

[9] Prokopakis, E., Vlastos, I.M., Tsagournisakis, M., Christodoulou, P., Kawauchi, H. and Velegrakis, G. (2013) Canalith Repositioning Procedures among 965 Patients with Benign Paroxysmal Positional Vertigo. Audiology and Neurotology, 18, 83-88. http://dx.doi.org/10.1159/000343579

[10] Prokopakis, E.P., Chimona, T., Tsagournisakis, M., Christodoulou, P., Hirsch, B.E., Lachanas, V.A., Helidonis, E.S., Plaitakis, A. and Velegrakis, G.A. (2005) Benign Paroxysmal Positional Vertigo: 10-Year Experience in Treating 592 Patients with Canalith Repositioning Procedure. Laryngoscope, 115, 1667-1671. http://dx.doi.org/10.1097/01.mlg.0000175062.36144.b9

[11] Tevzadze, N. and Shakarishvili, R. (2007) Effectiveness of Canalith Repositioning Manoeuvers (CRM) in Patients with Benign Paroxysmal Positional Vertigo (BPPV). Georgian Medical News, 148-149, 40-44.

[12] Bhattacharyya, N., Baugh, R.F., Orvidas, L., Barrs, D., Bronston, L.J., Cass, S. and Haidari, J. (2008) Clinical Practice Guideline: Benign Paroxysmal Positional Vertigo. Otolaryngology—Head \& Neck Surgery, 139, S47-S81. http://dx.doi.org/10.1016/j.otohns.2008.08.022

[13] Furman, J.M. and Cass, S.P. (1999) Benign Paroxysmal Positional Vertigo. The New England Journal of Medicine, 341, 1590-1596. http://dx.doi.org/10.1056/NEJM199911183412107

[14] Campbell, K. (1997) Essential Audiology for Physicians. Singular Publishing Group, San Diego.

[15] Jacobson, G.P., Newman, C.W. and Kartush, J.M. (1993) Handbook of Balance Function Testing. Singular Publishing Group, San Diego.

[16] Barber, H.O. and Stockwell, C.W. (1976) Manual of Electronystagmography. Mosby, St. Louis.

[17] The Role of Videonystagmography (VNG), American Academy of Audiology. A Comparison between ENG and VNG.

[18] Ganança, M.M., Caovilla, H.H. and Ganança, F.F. (2010) Electronystagmography versus Videonystagmography. Brazilian Journal of Otorhinolaryngology, 76. http://dx.doi.org/10.1590/S1808-86942010000300021

[19] McCaslin, D.L. and Jacobson, G.P. (2009) Current Role of the Videonystagmography Examination in the Context of the Multidimensional Balance Function Test Battery. Seminars in Hearing, 30, 242-253.

[20] McCaslin, D.L. PhD. Electronystagmography/Videonystagmography (ENG/VNG). 
Scientific Research Publishing (SCIRP) is one of the largest Open Access journal publishers. It is currently publishing more than 200 open access, online, peer-reviewed journals covering a wide range of academic disciplines. SCIRP serves the worldwide academic communities and contributes to the progress and application of science with its publication.

Other selected journals from SCIRP are listed as below. Submit your manuscript to us via either submit@scirp.org or Online Submission Portal.
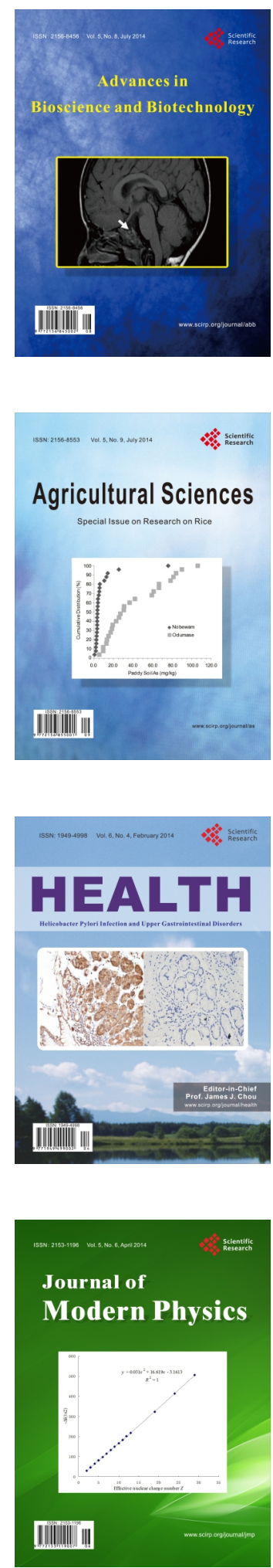
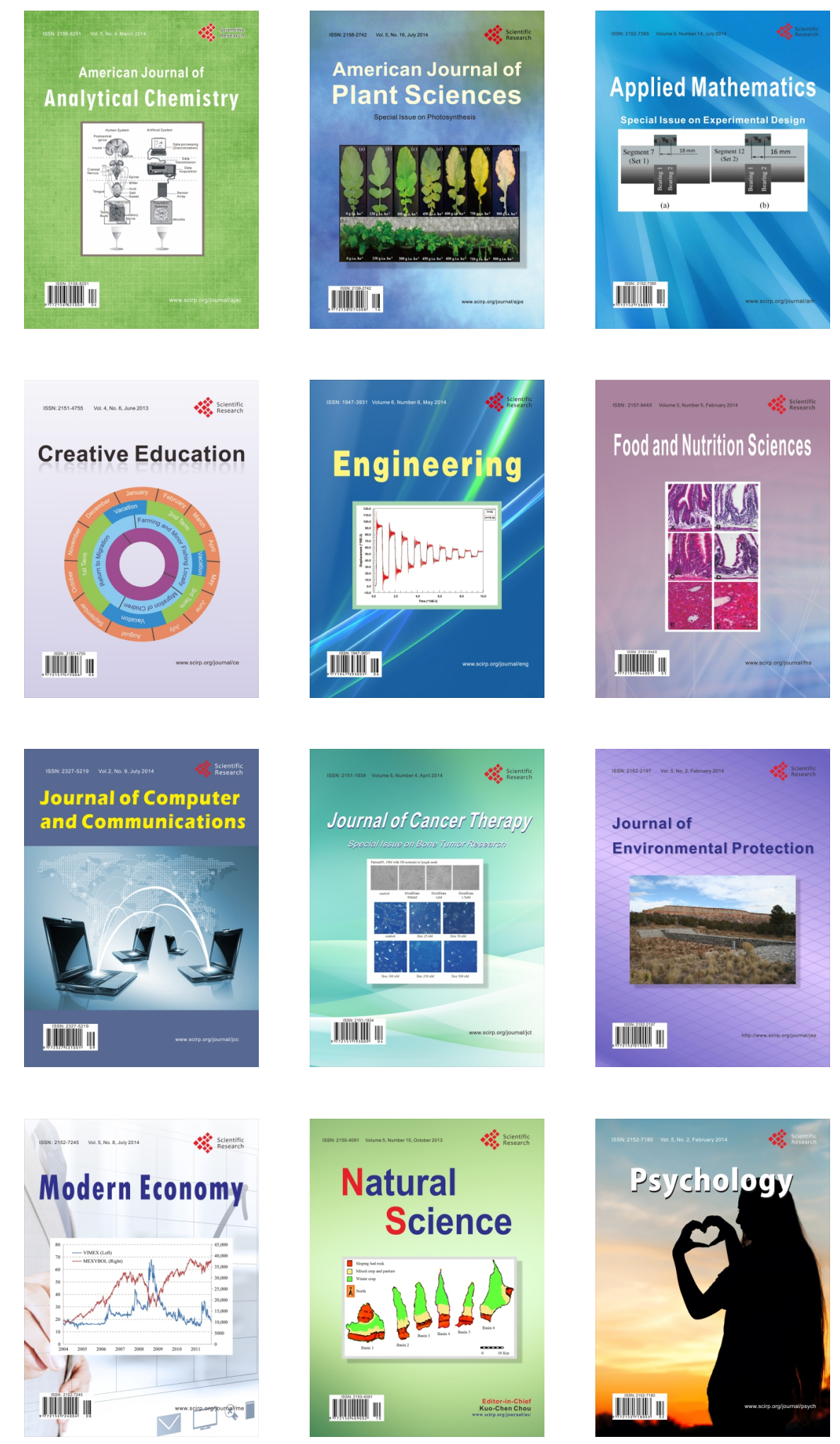